\title{
Extraglottic airway devices: technology update
}

This article was published in the following Dove Press journal:

Medical Devices: Evidence and Research

17 August 2017

Number of times this article has been viewed

\section{Bimla Sharma \\ Chand Sahai \\ Jayashree Sood}

Department of Anaesthesiology, Pain and Perioperative Medicine, Sir Ganga Ram Hospital, New Delhi, India
Correspondence: Bimla Sharma

Department of Anaesthesiology, Pain and Perioperative Medicine, Sir Ganga Ram Hospital, Old Rajinder Nagar, New Delhi 110060 , India

Tel +9I II 42252523

Fax +9। II $2586 \quad 002$

Email bimsharma@rediffmail.com
Abstract: Extraglottic airway devices (EADs) have revolutionized the field of airway management. The invention of the laryngeal mask airway was a game changer, and since then, there have been several innovations to improve the EADs in design, functionality, safety and construction material. These have ranged from changes in the shape of the mask, number of cuffs and material used, like rubber, polyvinylchloride and latex. Phthalates, which were added to the construction material in order to increase device flexibility, were later omitted when this chemical was found to have serious adverse reproductive outcomes. The various designs brought out by numerous companies manufacturing EADs resulted in the addition of several devices to the airway market. These airway devices were put to use, many of them with inadequate or no evidence base regarding their efficacy and safety. To reduce the possibility of compromising the safety of the patient, the Difficult Airway Society (DAS) formed the Airway Device Evaluation Project Team (ADEPT) to strengthen the evidence base for airway equipment and vet the new extraglottic devices. A preuse careful analysis of the design and structure may help in better understanding of the functionality of a particular device. In the meantime, the search for the ideal EAD continues.

Keywords: extraglottic airway devices, laryngeal mask airway, other extraglottic airway devices, safety, technology update

\section{Introduction}

Extraglottic airway devices (EADs) have revolutionized the field of airway management. These devices also known as supraglottic airway devices or supralaryngeal airways are orally inserted with their distal ends lying in the hypopharynx or esophagus. The American Standards for Testing Materials (ASTM) Committee F29 on Anesthetic and Respiratory Equipment has defined supraglottic airway devices as "Airways that are intended to open, secure, and seal the supraglottic area to provide an unobstructed airway in spontaneously breathing or ventilated patients, typically during anesthetic procedures." The devices produced according to the ASTM facilitate unobstructed access of respiratory gases to glottic inlet by displacing tissue, do not require an (external) facial seal to maintain airway patency, terminate in a $15 / 22-\mathrm{mm}$ connector to facilitate positive pressure ventilation via an anesthetic breathing system, are capable of maintaining airway patency when the $(15 / 22-\mathrm{mm})$ airway connector is open to ambient atmosphere and minimize escape of airway gases to the ambient. They are used for primary airway management and rescue ventilation when face mask ventilation is difficult, and as a conduit for endotracheal intubation. There has been a plethora of airway devices and equipment in the market (Figure 1). New EADs have 


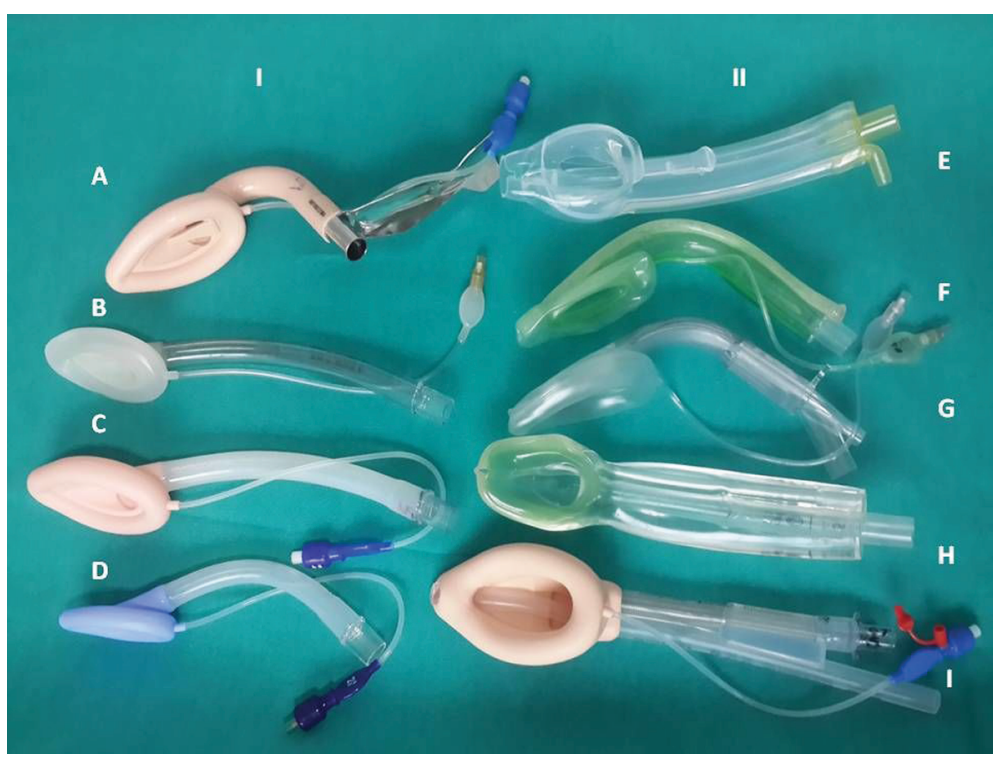

Figure I (I) Extraglottic devices with airway tube only: (A) intubating laryngeal mask airway (B) LMA Unique ${ }^{\mathrm{TM}}$, (C) classic LMA and (D) disposable laryngeal mask (Romsons). (II) Extraglottic devices with both airway and drain tube: (E) Baska mask, (F) Ambu AuraGain ${ }^{\mathrm{TM}}$, (G) LMA Supreme LM, $^{\mathrm{TM}}$ (H) i-gel and (I) ProSeal ${ }^{\mathrm{TM}}$ laryngeal mask airway. Abbreviation: LMA, laryngeal mask airway.

been described at a rate of one per year for the last 25 years, increasing to two per year since the turn of the century. ${ }^{2}$ Unfortunately, not all the devices have been tested with apropos evidence pertaining to their clinical performance or safety. This concern prompted the Difficult Airway Society (DAS) to form the Airway Device Evaluation Project Team (ADEPT), which was tasked with formulating a method to formally evaluate equipment associated with airway management regarding safety issues and clinical performance based on solid evidence. ${ }^{3}$

Technology has tremendous significance in today's complex professional environment with special emphasis on patient safety. Up-to-date solutions can make for more efficient, cost-effective performance, conserving time and resources. With any new scientific advancement or technology, there is a learning curve followed by clinical studies which evaluate the newly acquired technology for its benefits, limitations and side effects. This review covers the technology aspects of these EADs.

\section{Objective}

This review was performed to assess and evaluate the update on technology aspects and design specifications of various extraglottic devices in current use.

\section{Design}

This is a narrative systematic review of the randomized controlled trials (RCTs) and the other available literature on extraglottic devices in contemporary use.

\section{Methods}

The first two authors independently searched PubMed and Cochrane Database of Systematic Reviews (1935-2017). Data were also obtained from textbooks. The keywords used for PubMed and Cochrane Database of Systematic Reviews were extraglottic airway devices, laryngeal mask airway, other extraglottic airway devices, safety and technology update. A total of 86 articles were selected. Among these, there were 14 review articles including three metaanalyses, 16 comparative studies and two articles from books (Table 1).

Table I Data source

\begin{tabular}{lll}
\hline Keywords & PubMed & $\begin{array}{l}\text { Cochrane Database } \\
\text { of Systematic Reviews }\end{array}$ \\
\hline Extraglottic airway devices & 60 & 19 \\
Laryngeal mask airway & 5878 & 10 \\
$\begin{array}{l}\text { Other extraglottic airway devices } \\
\text { Extraglottic airway devices and }\end{array}$ & 9 & 0 \\
$\begin{array}{l}\text { safety } \\
\text { Extraglottic airway devices }\end{array}$ & 0 & 0 \\
technology update & 0 & 0 \\
$\begin{array}{l}\text { Extraglottic airway devices and } \\
\text { technology update }\end{array}$ & 0 & 2 \\
$\begin{array}{l}\text { Supraglottic airway devices } \\
\text { Other supraglottic airway devices }\end{array}$ & 118 & 2 \\
$\begin{array}{l}\text { Supraglottic airway devices and } \\
\text { safety }\end{array}$ & 60 & 2 \\
$\begin{array}{l}\text { Supraglottic airway devices } \\
\text { technology update }\end{array}$ & 0 & 0 \\
$\begin{array}{l}\text { Supraglottic airway devices and } \\
\text { technology update }\end{array}$ & 0 & 0 \\
\hline
\end{tabular}




\section{Elimination criteria}

The articles related to EADs not inserted orally (tracheostomy) and those not so popular and in current use (eg, the Elisha device) were not included. The articles which did not provide information on construction material, functional evolution, safety issues and technology updates were also excluded.

\section{Classification of devices}

Classification of the EADs parallels their design and functional evolution. There are several criteria for classifying the EADs based on variations ranging from cuffed versus noncuffed, the number of cuffs, location of the distal end in relation to glottis, sealing mechanism, perilaryngeal versus base of tongue, reusable versus disposable, protection against aspiration and chronological order (though objections were raised regarding this, further complicating the classification) to increasingly complex variations of the original designs. ${ }^{4-7}$

\section{Cuffed versus noncuffed}

Devices such as classic laryngeal mask airway (cLMA) and ProSeal $^{\mathrm{TM}}$ laryngeal mask airway (PLMA) are cuffed, while i-gel and Baska mask are examples of noncuffed devices, the latter having the advantages of avoiding the problems associated with cuff-related morbidity. The flip side is that they may be accompanied with increased risks of leaks and associated problems. ${ }^{8}$ The cuffless devices could offer the advantage of being magnetic resonance (MR) compatible by obviating the ferromagnetic material in the pilot balloon of the cuff inflation assembly.

\section{Location of the distal end in relation to glottis}

Supraglottic devices seal around the glottic inlet and remain superior to the larynx (eg, cLMA, PLMA and Ambu masks). Retroglottic devices are laryngeal tubes that terminate in the upper esophagus, remaining posterior to the glottis (eg, Laryngeal Tube [LT] and Laryngeal Tube Suction II [LTS-II]).

\section{Sealing mechanism: perilaryngeal versus base of tongue}

Base-of-tongue sealers such as LT, LTS-II, Streamlined Liner of the Pharynx Airway (SLIPA) and Cobra Perilaryngeal Airway (Cobra PLA ${ }^{\mathrm{TM}}$ ) are also known as pharyngeal sealers. The laryngeal mask airways (LMAs) and laryngeal masks (LMs) seal the perilaryngeal area and are known as perilaryngeal sealers. The cLMA, invented by Dr Archie IJ Brain, was the first perilaryngeal sealer.

\section{Reusable versus disposable}

Original EADs (cLMA, LTS) were manufactured as reusable equipment; however, disposable devices (eg, i-gel, Ambu AuraGain) now available are cheaper and easier to maintain than the reusable devices and preclude concerns about prion disease. Disposable devices are of special importance in the following situations: 1) resuscitation and field situations and 2) prevention of disease transmission.

\section{Protection against aspiration}

The addition of a gastric tube such as PLMA, i-gel and devices with reservoir (eg, SLIPA) provides some protection against aspiration. Higher oropharyngeal seal pressure (OSP), the first seal and the hypopharyngeal seal, the second seal, are important safety factors for protection against aspiration (eg, PLMA). The SLIPA has a different mechanism separating respiratory and gastrointestinal tracts and allowing storage of gastric fluid, being a hollow liner of the pharynx under pressure, thus providing a liquid trap within the device. ${ }^{9}$

\section{Device generation}

The idea of classifying the EADs as first or second generation was introduced by Cook and Howes. ${ }^{10}$ The first-generation EADs fit the description "simple airway devices". These airway devices have a single airway tube. They are devoid of any specific design characteristics aimed at reducing the risk of pulmonary aspiration of gastric contents. The classic examples of first-generation devices are LMA and Combitube, both of which became available during the second half of the 1980s. On the other hand, the second-generation EADs (PLMA, i-gel) incorporate specific design features to improve positive pressure ventilation and reduce the risk of aspiration.

A controversial new term, third-generation EADs, has been introduced in anesthesia literature. Initially, the term was used to indicate facilitated intubation through EADs. ${ }^{11}$ However now, the term is used to denote the presence of a self-energizing sealing cuff (Baska). No consensus has been reached regarding the classification of these devices; therefore, a proper scientific classification of extraglottic airways is still awaited.

\section{Design evolution}

The first device which can be described as extraglottic was introduced by Dr Francis Shipway in 1935, a pharyngeal airway comprising an inflatable rubber balloon added to the shaft of the Guedel airway to prevent aspiration of blood during nasal procedures. ${ }^{12}$ Two years later, a Canadian doctor Beverley Charles Leech invented a "pharyngeal bulb gasway" 
which would fit more closely to the larynx. It consisted of an anatomically shaped, hollow rubber bulb which would be stuck in the pharynx. ${ }^{13}$ However, neither device became popular.

It took almost 50 years for another supraglottic airway (LMA) to be designed in 1983. The LMA consists of an airway tube connected to an inflatable mask. ${ }^{14}$ The invention of the LMA was a game changer in airway management, and it came about when Brain came across two difficult airway scenarios in his practice. An inspiring lecture about airway management needing a new direction by Dr Lucien Morris, an American anesthesiologist, led to Brain renewing his work on an alternate airway device which would be somewhere between a face mask and an endotracheal tube, and he came up with the LMA. Of course, the final product was created after much experimentation, making plaster casts of cadaver larynxes, using a combination of the Goldman nasal mask (used for dental anesthesia) and a diagonally slit red rubber endotracheal tube. The obstacles on the way to making a device that was capable of changing the management of the difficult airway were many: discovering the appropriate material for the cuff, safety design issues (how to keep the epiglottis from obstructing the airway), misinterpretation of experimental LMs as being of sexual nature and even after the LMA was commercially manufactured being chastised by a religious society for producing such "evil things"; acceptance of the device by a skeptical anesthesia community, and the last but not the least, finding someone to finance the manufacturing of the LMA. ${ }^{15}$

\section{Specific EADs}

A brief review of EADs in common use is given below.

\section{LMA family}

The LMA standard, now known as cLMA, was the first airway device to directly encircle the laryngeal structures with the end of its bowl located very close to the vocal cords. ${ }^{13}$ The development of LMA continued, with several additions to its family (Figure 2): the LMA Unique ${ }^{\mathrm{TM}}$, a disposable device ready to use especially in field scenarios and to avoid cross contamination and prevention of certain diseases; the LMA Flexible designed for intraoral procedures and the Intubating LMA (Fastrach) which allowed blind intubation through the device in difficult airway scenarios. ${ }^{16,17}$ The addition of integrated fiber optics with a monitor resulted in the LMA CTrach which visualized the dynamics of tracheal intubation. The ProSeal and LMA Supreme ${ }^{\mathrm{TM}}$ have a gastric or drain tube in addition to the airway tube separating the respiratory and the gastrointestinal tracts. ${ }^{18-20}$

\section{cLMA}

It consists of a mask with an inflatable cuff and an airway tube connecting the mask to the anesthesia circuit or a selfinflating bag. It can easily be placed by paramedics. However,

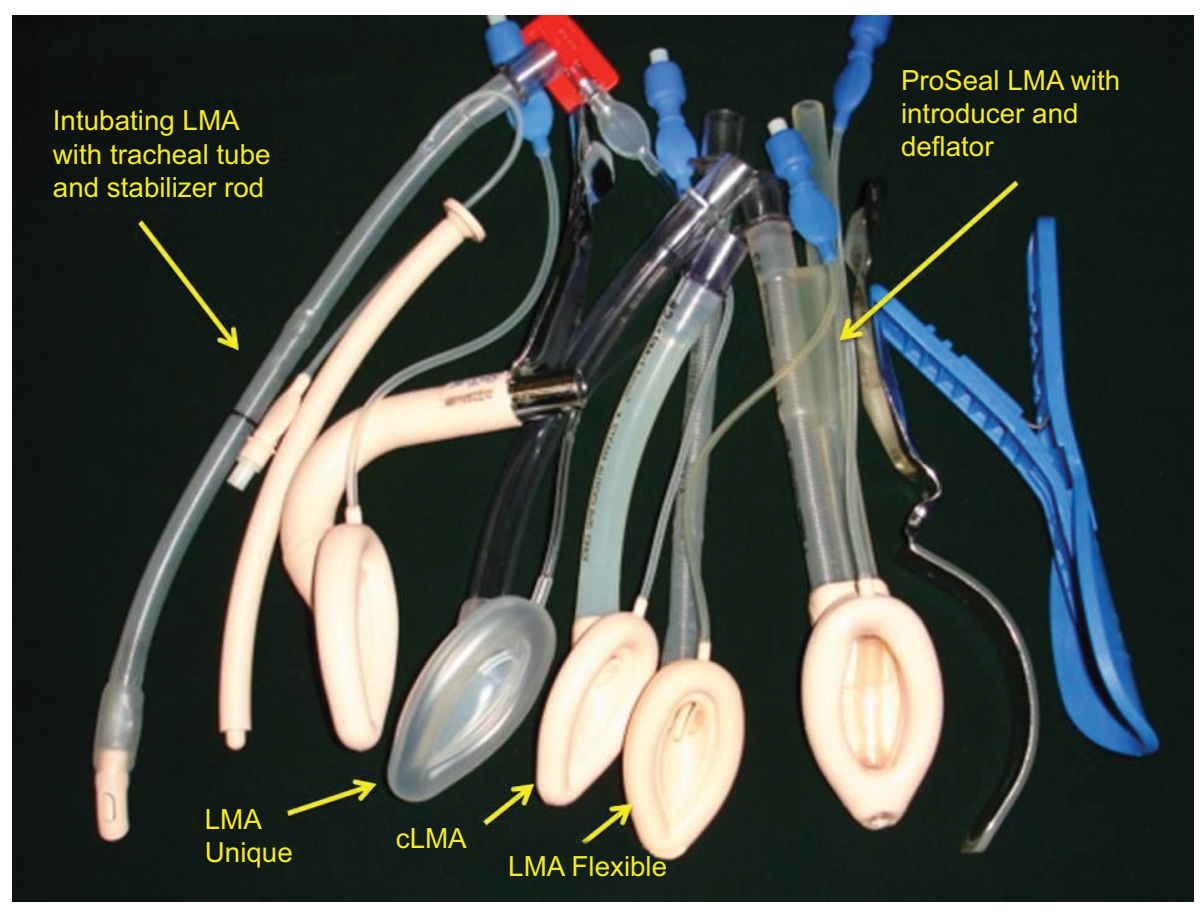

Figure 2 LMA family.

Abbreviations: LMA, laryngeal mask airway; CLMA, classic LMA. 
the device provides low OSP (10-20 $\left.\mathrm{cm} \mathrm{H}_{2} \mathrm{O}\right)$, may produce gastric insufflation and offers no protection against pulmonary aspiration (Figure 3$).^{21}$

\section{ProSeal LMA}

It is a reusable device with dorsal and ventral cuffs allowing for a higher OSP and a drain tube to access to the gastrointestinal tract. The airway and the drain tubes are joined together to form the rigid bite block which prevents obstruction in case the patient bites it (Figure 4). ${ }^{19}$

\section{LMA Supreme}

The LMA Supreme is a disposable version of PLMA with a reinforced cuff preventing folding of the mask with an oval airway cross section for more stability to the device. It has a built-in bite block and fixation tab to secure the airway. Its

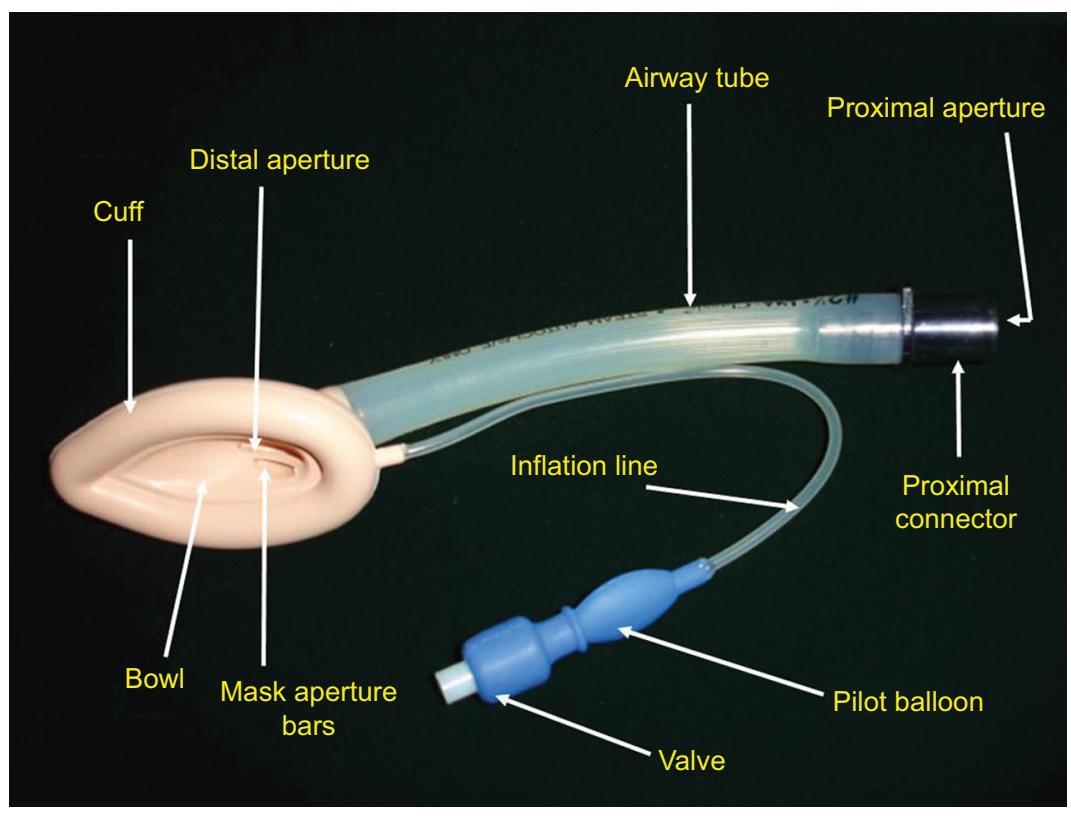

Figure 3 Classic LMA.

Abbreviation: LMA, laryngeal mask airway.

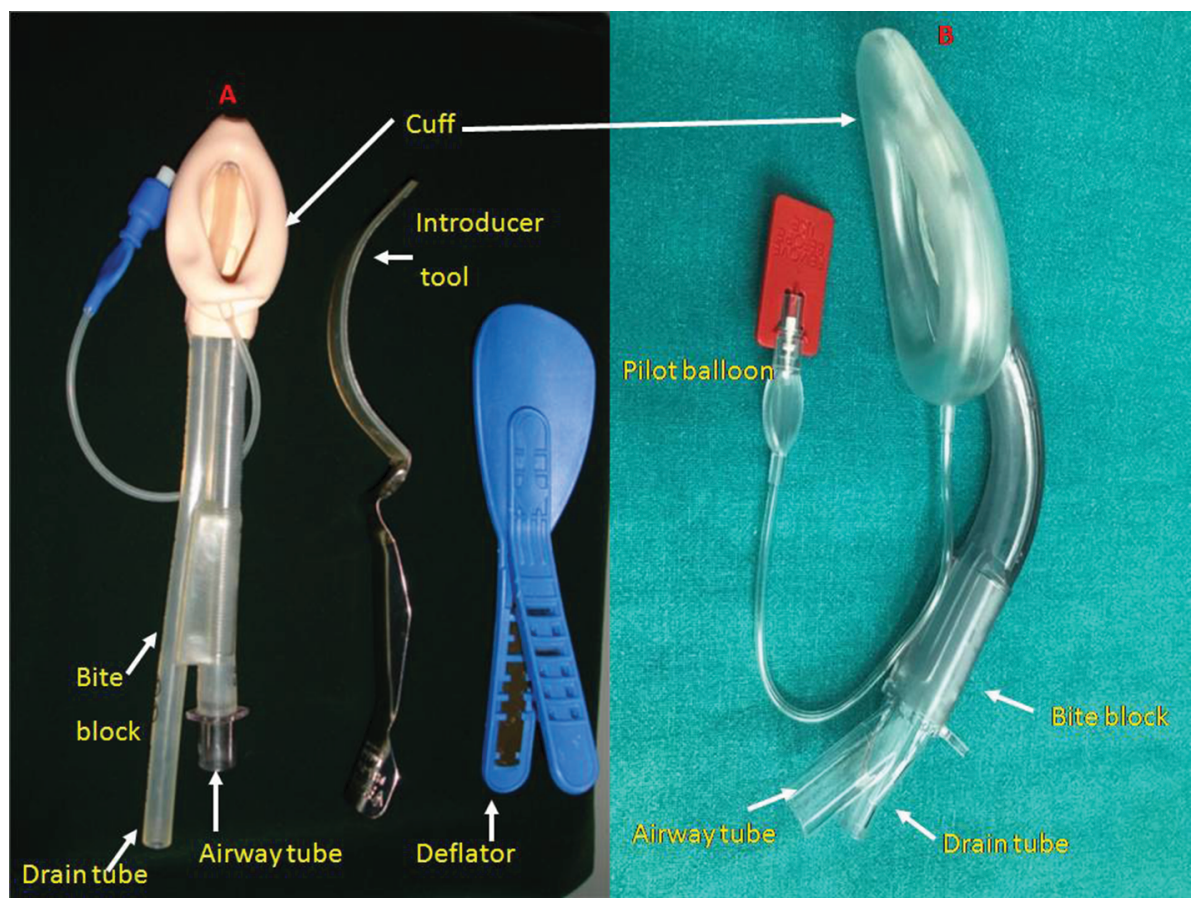

Figure 4 (A) ProSeal ${ }^{\mathrm{TM}}$ LMA. (B) LMA Supreme ${ }^{\mathrm{TM}}$.

Abbreviation: LMA, laryngeal mask airway. 
performance is comparable to the PLMA and superior to the cLMA (Figure 4). ${ }^{20}$

\section{LMs and others}

Encouraged by the success of this device, many other EADs have subsequently been invented since 1990s. Devices with a similar design to the LMA family are known as LMs and were introduced in the following years (eg, AuraOnce, SoftSeal ${ }^{\circledR}$ or Solus LMs). ${ }^{7,22}$ The designs of other EADs differed from that of the LMA family devices such as the SLIPA, Elisha airway device, i-gel, Cobra PLA or LT, LTS-II, intubating laryngeal airway, intubating Laryngeal Tube Suction Disposable (iLTS-D), Baska mask and Totaltrack VLM (Figure 5). ${ }^{9,23-32}$

\section{LT and LTS-II}

The LT and LTS-II comprise a simple airway tube with oropharyngeal and esophageal cuffs with an opening between the two cuffs for the passage of gas into the larynx. The LTS-II has an additional lumen opening into the esophagus beyond the distal cuff. Similar to the Combitube, its use is recommended only for emergencies or failure to intubate and ventilate. ${ }^{33,34}$ The LTS-II has a high oropharyngeal seal, and insertion of the device is considered easy. Postinsertion ventilation is less reliable than that with the PLMA, and the device is associated with a relatively high rate of airway obstruction and occasional glottic placement has been reported. The device is not suitable as a tracheal tube conduit due to its small airway orifice.

\section{Cobra PLA}

Its tip is shaped like the head of a Cobra and has a grating allowing for ventilation while avoiding obstruction. Just proximal to the tip of the device is a low-pressure and largevolume pharyngeal cuff. It was found to be similar to the cLMA in terms of ease of insertion but achieved higher sealing pressures and can be used for airway rescue (Figure 5). ${ }^{27,35}$

\section{Streamlined Liner of the Pharynx Airway}

This is a cuffless device, pre-shaped to sit in the pharynx, with a heel and a hump to fit the soft palate and the base of the tongue, respectively. It has a hollow chamber that can store up to 50 $\mathrm{mL}$ of drained gastric fluid. It was designed for short general anesthetic procedures. A study in children comparing SLIPA and LMA Unique reported that SLIPA provided a better airway seal and stability. ${ }^{36}$ Another study reported that the SLIPA offers

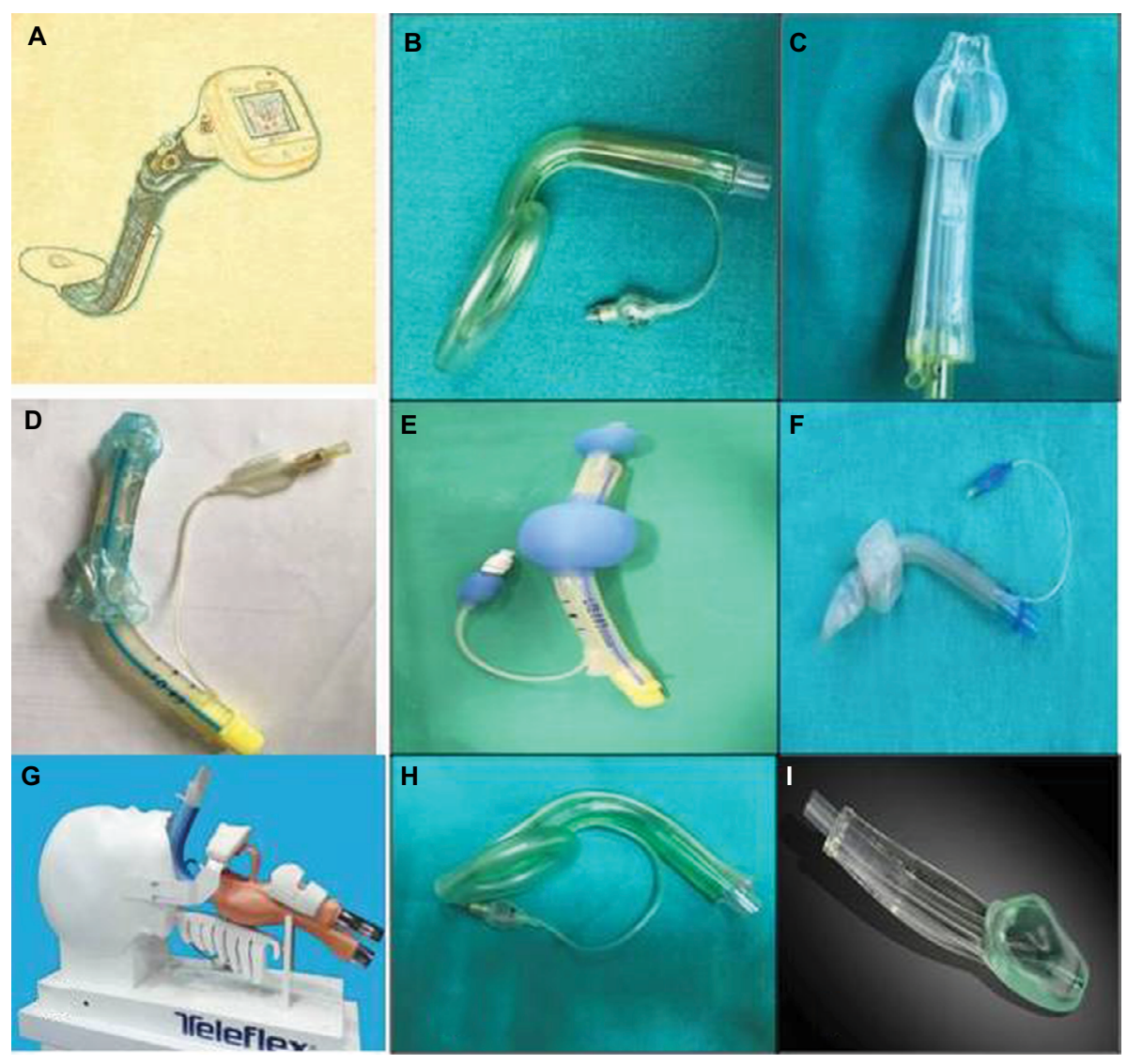

Figure 5 Laryngeal mask and others: (A) Totaltrack VLM, (B) Ambu mask, (C) Baska mask, (D) Laryngeal Tube, (E) Laryngeal Tube Suction, (F) Cobra PLA ${ }^{\mathrm{TM}}$, (G) LMAProtector ${ }^{\mathrm{TM}}$, (H) Ambu AuraGain and (I) i-gel.

Abbreviations: PLA, Perilaryngeal Airway; LMA, laryngeal mask airway. 
the advantage of less perilaryngeal gas leakage than the PLMA with change in head position and during insufflation of the peritoneal cavity. ${ }^{37}$ SLIPA can be used as a useful alternative to PLMA in patients undergoing lower abdominal laparoscopic surgery with muscle relaxant and controlled ventilation.

Epiglottic downfolding was reported to be significantly lower with the SLIPA as compared to the PLMA in patients undergoing lower abdominal laparoscopic surgery (Figure 6).$^{38}$

\section{i-gel}

It is a single-use preshaped cuffless device, made of a gel-like material. The shape, softness and contours accurately mirror the perilaryngeal anatomy. There is also a narrow drain tube for insertion of a gastric tube. It is easy to insert, MR safe and allows a standard high-diameter tracheal tube to negotiate through the airway tube. The OSP and the gastric insertion rates are comparable with PLMA, but the insertion time is shorter and the incidence of sore throat is lower (Figure 5).$^{39}$

\section{Ambu AuraGain}

It is an anatomically curved single-use device and can be easily inserted. It integrates gastric access and intubation capability. It is made up of phthalate-free material and is MR safe. Similar to PLMA, it has an integrated bite block which prevents airway occlusion. Pilot balloon identifies mask size and provides tactile indication of degree of inflation. There are navigation marks for guiding flexible scope. The pilot balloon identifies mask size. A study comparing it with LMA Supreme reported that both devices had similar OSPs but the AuraGain resulted in less postoperative sore throat despite being harder and taking longer to insert (Figure 5). ${ }^{40}$

\section{Baska mask}

The Baska mask is a new noncuffed EAD which provides a superior seal as compared to the cLMA. It also has additional

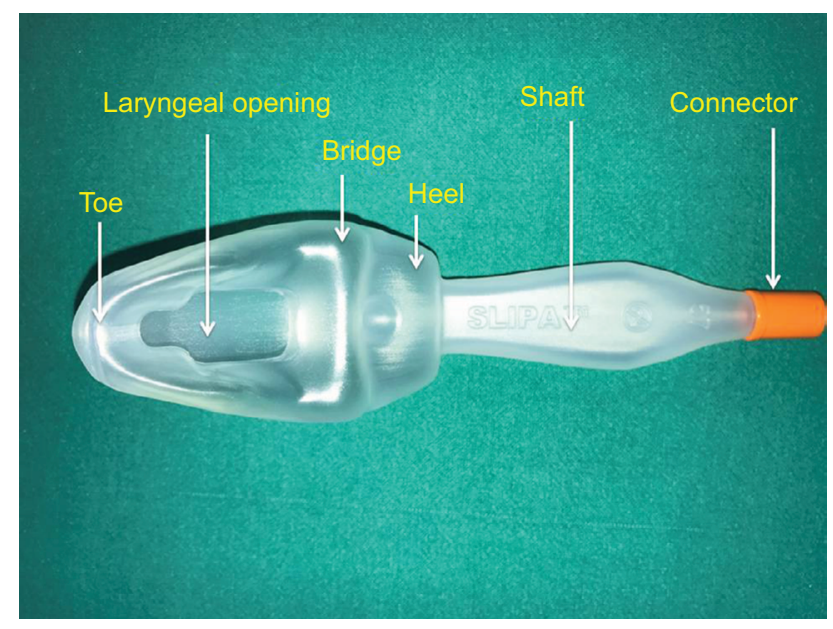

Figure 6 Streamlined Liner of the Pharynx Airway. safety features: 1) a large sump cavity with two aspiratable gastric drain tubes; 2) a tab for manually curving the mask to ease insertion; and 3) a suction elbow integral to one port with a second port acting as a free air flow access. The drain tubes can also work as ventilatory tubes in case the ventilatory tube gets obstructed. These features may reduce the risk of pulmonary aspiration of secretions or gastric contents that accumulate in the supraglottic area (Figure 5). ${ }^{31}$

The details of a few specific EADs are given in Table 2 , and the salient features of some EADs are discussed as follows.

\section{Mask, cuff and bowl}

EADs have masks with or without inflatable cuffs. The cuff could be part of the LMAs, the LMs or the pharyngeal sealers. The i-gel has a mask with a non-inflatable gel-filled cuff. A larger cuff as seen in the PLMA with its posterior component improves the oropharyngeal seal without increasing the cuff pressure. ${ }^{41}$ Both the LMA Supreme and LMA-Protector ${ }^{\mathrm{TM}}$ have reinforced tips to prevent posterior folding of the mask. The cuff of Ambu mask is tapered at the tube. The Baska mask and the recently introduced LMA-Protector have selfenergizing cuffs. ${ }^{31,42}$

The earlier introduced pharyngeal sealers had single cuffs. However, the present pharyngeal sealers have two cuffs: the smaller hypopharyngeal and the bigger pharyngeal which forms a seal with the respiratory tract (eg, LT, LTS-II and iLTS-D). The iLTS-D, a modified LT, allows intubation similar to an intubating LM.

A deeper bowl of the mask is superior to a shallow bowl as it improves the oropharyngeal seal. The PLMA has a larger and deeper mask bowl which lacks the semirigid shell of the cLMA. A correctly placed PLMA provides higher OSP (10 $\mathrm{cm} \mathrm{H}_{2} \mathrm{O}$ or more) than the cLMA. The storage capacity of the cLMA is only $4 \mathrm{~mL}$ in comparison to $50 \mathrm{~mL}$ of that of SLIPA device, and therefore, the risks of aspiration with regurgitation are theoretically higher (Figure 7). ${ }^{9}$

\section{Mask aperture bars (MABs), epiglottis- elevating bar, Cobra head, fins and epiglottic rest}

The original cLMA was developed with two MABs to prevent the epiglottis from obstructing the airway; nevertheless, its function has been questioned as the presence of MABs may interfere with endotracheal intubation if it is necessary to pass a tube through the EAD. ${ }^{43-46}$ Several of the newer EADs (Baska and LMA-Protector) have no MABs, while others contain a varying number of epiglottic bars or show 
Table 2 Some features of various extraglottic airway devices

\begin{tabular}{|c|c|c|c|c|c|}
\hline $\begin{array}{l}\text { Extraglottic airway } \\
\text { device, year of } \\
\text { manufacture, } \\
\text { construction material }\end{array}$ & Sealing site & Strengths & Weaknesses & Effectiveness & Safety of the device \\
\hline \multirow[t]{3}{*}{ cLMA, 1988, silicone* } & Perilaryngeal & Easy to insert & Low OSP & $\begin{array}{l}\text { Short elective surgical } \\
\text { procedures }\end{array}$ & Simple to use \\
\hline & & & No integrated bite block & $\begin{array}{l}\text { Difficult and failed } \\
\text { intubation }\end{array}$ & $\begin{array}{l}\text { No aspiration } \\
\text { protection }\end{array}$ \\
\hline & & & No malposition diagnosis & & $\begin{array}{l}\text { Mainly for spontaneous } \\
\text { respiration }\end{array}$ \\
\hline $\begin{array}{l}\text { LMA Flexible, I990, } \\
\text { silicone* and PVC }\end{array}$ & Perilaryngeal & $\begin{array}{l}\text { Reinforced, long, narrow, } \\
\text { airway tube } \\
\text { Designed for intraoral } \\
\text { procedures }\end{array}$ & $\begin{array}{l}\text { Low OSP } \\
\text { No malposition diagnosis } \\
\text { Difficult insertion } \\
\text { No integrated bite block }\end{array}$ & $\begin{array}{l}\text { Short elective surgical } \\
\text { procedures }\end{array}$ & $\begin{array}{l}\text { No aspiration } \\
\text { protection }\end{array}$ \\
\hline \multirow[t]{2}{*}{$\begin{array}{l}\text { LMA Unique }{ }^{\mathrm{TM}}, 1997, \\
\text { PVC }\end{array}$} & Perilaryngeal & Easy to insert & Low OSP & $\begin{array}{l}\text { Short elective surgical } \\
\text { procedures }\end{array}$ & $\begin{array}{l}\text { No aspiration } \\
\text { protection }\end{array}$ \\
\hline & & Disposable & $\begin{array}{l}\text { No malposition diagnosis } \\
\text { No integrated bite block }\end{array}$ & $\begin{array}{l}\text { Field situations } \\
\text { Difficult and failed } \\
\text { intubation }\end{array}$ & $\begin{array}{l}\text { Mainly for spontaneous } \\
\text { respiration }\end{array}$ \\
\hline \multirow[t]{2}{*}{$\begin{array}{l}\text { Intubating LMA, I997, } \\
\text { silicone* and PVC }\end{array}$} & Perilaryngeal & Easy to use & $\begin{array}{l}\text { High incidence of airway } \\
\text { morbidity }\end{array}$ & $\begin{array}{l}\text { Primary use in adult } \\
\text { difficult and failed } \\
\text { intubation }\end{array}$ & $\begin{array}{l}\text { Failure rates are higher } \\
\text { for blind intubation } \\
\text { versus lightwand- or } \\
\text { fiber optic-guided } \\
\text { intubation }\end{array}$ \\
\hline & & $\begin{array}{l}\text { Short wide rigid tube to } \\
\text { accommodate ETT } \\
\text { Integrated bite block }\end{array}$ & Pediatric sizes not available & High success rate & $\begin{array}{l}\text { No aspiration } \\
\text { protection }\end{array}$ \\
\hline \multirow[t]{2}{*}{ PLMA, 2000, silicone* } & Perilaryngeal & High OSP & $\begin{array}{l}\text { First time success rate and } \\
\text { insertion time longer than } \\
\text { cLMA, bulky cuff }\end{array}$ & $\begin{array}{l}\text { Allows ventilation at } \\
\text { higher airway pressures }\end{array}$ & Reliable seal \\
\hline & & $\begin{array}{l}\text { Displacement diagnosis } \\
\text { Reinforced airway tube, } \\
\text { drain tube } \\
\text { Integrated bite block } \\
\text { present }\end{array}$ & $\begin{array}{l}\text { Posterior folding of mask } \\
\text { causing obstruction of } \\
\text { drain tube }\end{array}$ & $\begin{array}{l}\text { Mainly devised for IPPV } \\
\text { Difficult and failed } \\
\text { intubation }\end{array}$ & $\begin{array}{l}\text { Some aspiration } \\
\text { protection }\end{array}$ \\
\hline \multirow[t]{2}{*}{$\begin{array}{l}\text { LMA Supreme }{ }^{\mathrm{TM}}, 2005 \text {, } \\
\text { PVC }\end{array}$} & Perilaryngeal & $\begin{array}{l}\text { Elliptical preformed } \\
\text { semirigid airway tube, } \\
\text { drain tube }\end{array}$ & Similar to PLMA & $\begin{array}{l}\text { Shares features of } \\
\text { Intubating LMA and } \\
\text { PLMA }\end{array}$ & Reliable seal \\
\hline & & Disposable & $\begin{array}{l}\text { OSP may be less than } \\
\text { PLMA }\end{array}$ & $\begin{array}{l}\text { Difficult and failed } \\
\text { intubation }\end{array}$ & $\begin{array}{l}\text { Some aspiration } \\
\text { protection } \\
\text { Better fixation }\end{array}$ \\
\hline \multirow[t]{2}{*}{$\begin{array}{l}\text { LMA-Protector }{ }^{\mathrm{TM}}, 2015 \text {, } \\
\text { silicone* }\end{array}$} & Perilaryngeal & $\begin{array}{l}\text { Multipurpose dynamic } \\
\text { curve } \\
\text { MR safe, cuff pilot } \\
\text { technology }\end{array}$ & $\begin{array}{l}\text { Similar to PLMA though } \\
\text { no clinical data available }\end{array}$ & $\begin{array}{l}\text { Similar to PLMA though } \\
\text { no clinical data available }\end{array}$ & $\begin{array}{l}\text { Should perform better } \\
\text { than PLMA but no } \\
\text { clinical data available }\end{array}$ \\
\hline & & $\begin{array}{l}\text { Dual gastric channel and } \\
\text { suction port }\end{array}$ & & & $\begin{array}{l}\text { Phthalate-free dual } \\
\text { gastric ports }\end{array}$ \\
\hline \multirow[t]{2}{*}{$\begin{array}{l}\text { LT, 1999, silicone* and } \\
\text { PVC }\end{array}$} & Base of tongue & $\begin{array}{l}\text { Airway tube with } 2 \\
\text { inflatable balloons } \\
\text { Easy insertion }\end{array}$ & $\begin{array}{l}\text { Obstruction is not } \\
\text { uncommon }\end{array}$ & $\begin{array}{l}\text { Controlled ventilation is } \\
\text { usually possible } \\
\text { Difficult and failed } \\
\text { intubation }\end{array}$ & $\begin{array}{l}\text { No protection } \\
\text { aspiration } \\
\text { Easy atraumatic } \\
\text { insertion even by the } \\
\text { inexperienced }\end{array}$ \\
\hline & & $\begin{array}{l}\text { Disposable version also } \\
\text { available }\end{array}$ & & & Out-of-hospital use \\
\hline \multirow[t]{2}{*}{$\begin{array}{l}\text { King LTS-II, 2004, } \\
\text { silicone* and PVC }\end{array}$} & Base of tongue & High OSP & $\begin{array}{l}\text { Airway obstruction more } \\
\text { common }\end{array}$ & $\begin{array}{l}\text { Recommended for } \\
\text { emergencies or failed }\end{array}$ & $\begin{array}{l}\text { Provides better } \\
\text { protection than cLMA }\end{array}$ \\
\hline & & Drain tube present & $\begin{array}{l}\text { Insertion success rate } \\
\text { lower }\end{array}$ & $\begin{array}{l}\text { intubation and } \\
\text { ventilation }\end{array}$ & $\begin{array}{l}\text { Better ventilation, less } \\
\text { gastric insufflation as } \\
\text { compared to LT }\end{array}$ \\
\hline
\end{tabular}


Table 2 (Continued)

\begin{tabular}{|c|c|c|c|c|c|}
\hline $\begin{array}{l}\text { Extraglottic airway } \\
\text { device, year of } \\
\text { manufacture, } \\
\text { construction material }\end{array}$ & Sealing site & Strengths & Weaknesses & Effectiveness & Safety of the device \\
\hline $\begin{array}{l}\text { Cobra PLA }{ }^{\mathrm{TM}} \text { and Cobra } \\
\text { PLUS, 2003, PVC }\end{array}$ & Base of tongue & $\begin{array}{l}\text { Higher sealing pressure } \\
\text { than cLMA } \\
\text { Cobra head with ramp for } \\
\text { ETT }\end{array}$ & $\begin{array}{l}\text { A rigid head of device and } \\
\text { soft pharyngeal cuff }\end{array}$ & $\begin{array}{l}\text { Recommended for short } \\
\text { elective surgery } \\
\text { Difficult and failed } \\
\text { intubation }\end{array}$ & $\begin{array}{l}\text { No aspiration } \\
\text { protection }\end{array}$ \\
\hline $\begin{array}{l}\text { SLIPA, 2002, ethylene-vinyl } \\
\text { acetate copolymer }\end{array}$ & Base of tongue & $\begin{array}{l}\text { Cuffless } \\
\text { Accommodate up to } \\
50 \mathrm{~mL} \text { of drained gastric } \\
\text { fluid }\end{array}$ & $\begin{array}{l}\text { Larger number of sizes } \\
\text { required } \\
\text { Bloods on device more } \\
\text { frequent } \\
\text { No integrated bite block }\end{array}$ & $\begin{array}{l}\text { Designed for short } \\
\text { general anesthetic } \\
\text { procedures } \\
\text { OSP similar to PLMA }\end{array}$ & $\begin{array}{l}\text { Aspiration protection } \\
\text { similar to PLMA but } \\
\text { better than CLMA }\end{array}$ \\
\hline \multirow[t]{4}{*}{ i-gel, 2007, SEBS } & Perilaryngeal & Higher insertion success & Narrow drain tube & $\begin{array}{l}\text { OSP between cLMA and } \\
\text { PLMA }\end{array}$ & Reliable seal \\
\hline & & Cuffless & $\begin{array}{l}\text { Siting over hypopharynx } \\
\text { not as good as PLMA }\end{array}$ & $\begin{array}{l}\text { Suitable for spontaneous } \\
\text { and controlled } \\
\text { ventilation }\end{array}$ & Aspiration protection \\
\hline & & $\begin{array}{l}\text { Rigid tube working as bite } \\
\text { block }\end{array}$ & & $\begin{array}{l}\text { Difficult and failed } \\
\text { intubation }\end{array}$ & $\begin{array}{l}\text { Decrease } \\
\text { pharyngolaryngeal } \\
\text { morbidity }\end{array}$ \\
\hline & & Anatomic seal & & & MR safe \\
\hline \multirow[t]{2}{*}{ Baska, 20I2, silicone* } & Perilaryngeal & $\begin{array}{l}\text { Cuff inflation and } \\
\text { monitoring not required }\end{array}$ & $\begin{array}{l}\text { Insertion success rate } \\
\text { lower than PLMA }\end{array}$ & $\begin{array}{l}\text { Suitable for spontaneous } \\
\text { and controlled } \\
\text { ventilation }\end{array}$ & $\begin{array}{l}\text { Should provide better } \\
\text { protection against } \\
\text { aspiration }\end{array}$ \\
\hline & & Two gastric drainage ports & & $\begin{array}{l}\text { Difficult and failed } \\
\text { intubation }\end{array}$ & $\begin{array}{l}\text { Insufficient data } \\
\text { available }\end{array}$ \\
\hline \multirow[t]{3}{*}{ AuraOnce, 2007, PVC } & Perilaryngeal & $\begin{array}{l}\text { Preformed curve }\left(70^{\circ}\right) \\
\text { with convenient depth } \\
\text { marks }\end{array}$ & Low OSP & $\begin{array}{l}\text { Suitable for spontaneous } \\
\text { short elective } \\
\text { procedures }\end{array}$ & $\begin{array}{l}\text { No aspiration } \\
\text { protection }\end{array}$ \\
\hline & & Reinforced mask tip & No integrated bite block & $\begin{array}{l}\text { Difficult and failed } \\
\text { intubation }\end{array}$ & $\begin{array}{l}\text { Softer, more flexible } \\
\text { cuff than LMA }\end{array}$ \\
\hline & & $\begin{array}{l}\text { Higher insertion success } \\
\text { rate }\end{array}$ & & & $\begin{array}{l}\text { MR-safe new versions } \\
\text { phthalate free }\end{array}$ \\
\hline \multirow[t]{2}{*}{$\begin{array}{l}\text { Ambu AuraGain, 20I4, } \\
\text { PVC (phthalates free) }\end{array}$} & Perilaryngeal & $\begin{array}{l}\text { Higher insertion success } \\
\text { rate }\end{array}$ & Narrow drain tube & High OSP & $\begin{array}{l}\text { Should provide better } \\
\text { protection against } \\
\text { aspiration, not much } \\
\text { literature available }\end{array}$ \\
\hline & & $\begin{array}{l}\text { Short wide preformed } \\
\text { airway tube } \\
\text { Drain tube }\end{array}$ & & $\begin{array}{l}\text { Suitable for spontaneous } \\
\text { and controlled } \\
\text { ventilation } \\
\text { Difficult and failed } \\
\text { intubation }\end{array}$ & MR safe, phthalate free \\
\hline \multirow[t]{2}{*}{$\begin{array}{l}\text { Totaltrack VLM, } 2013 \text {, } \\
\text { PVC and silicone* }\end{array}$} & Perilaryngeal & $\begin{array}{l}\text { Allows simultaneous } \\
\text { ventilation and intubation } \\
\text { with continuous } \\
\text { visualization }\end{array}$ & Insufficient clinical data & $\begin{array}{l}\text { Suitable for spontaneous } \\
\text { and controlled } \\
\text { ventilation }\end{array}$ & $\begin{array}{l}\text { Difficult and failed } \\
\text { intubation }\end{array}$ \\
\hline & & $\begin{array}{l}\text { Dedicated aspiration } \\
\text { system of internal mask } \\
\text { secretions }\end{array}$ & & $\begin{array}{l}\text { Difficult and failed } \\
\text { intubation }\end{array}$ & $\begin{array}{l}\text { Allows positive } \\
\text { pressure oxygenation } \\
\text { in the ventilation, } \\
\text { intubation and } \\
\text { extubation mode with } \\
\text { continuous visualization } \\
\text { Insufficient clinical data }\end{array}$ \\
\hline
\end{tabular}

Note: *Medical-grade silicone.

Abbreviations: cLMA, classic LMA; OSP, oropharyngeal seal pressure; LMA, laryngeal mask airway; PVC, polyvinylchloride; ETT, endotracheal tube; IPPV, intermittent positive pressure ventilation; PLMA, ProSeal ${ }^{T M}$ LMA; MR, magnetic resonance; LT, Laryngeal Tube; LTS-II, Laryngeal Tube Suction II; PLA, Perilaryngeal Airway; SLIPA, Streamlined Liner of the Pharynx Airway; SEBS, styrene ethylene butadiene styrene. 

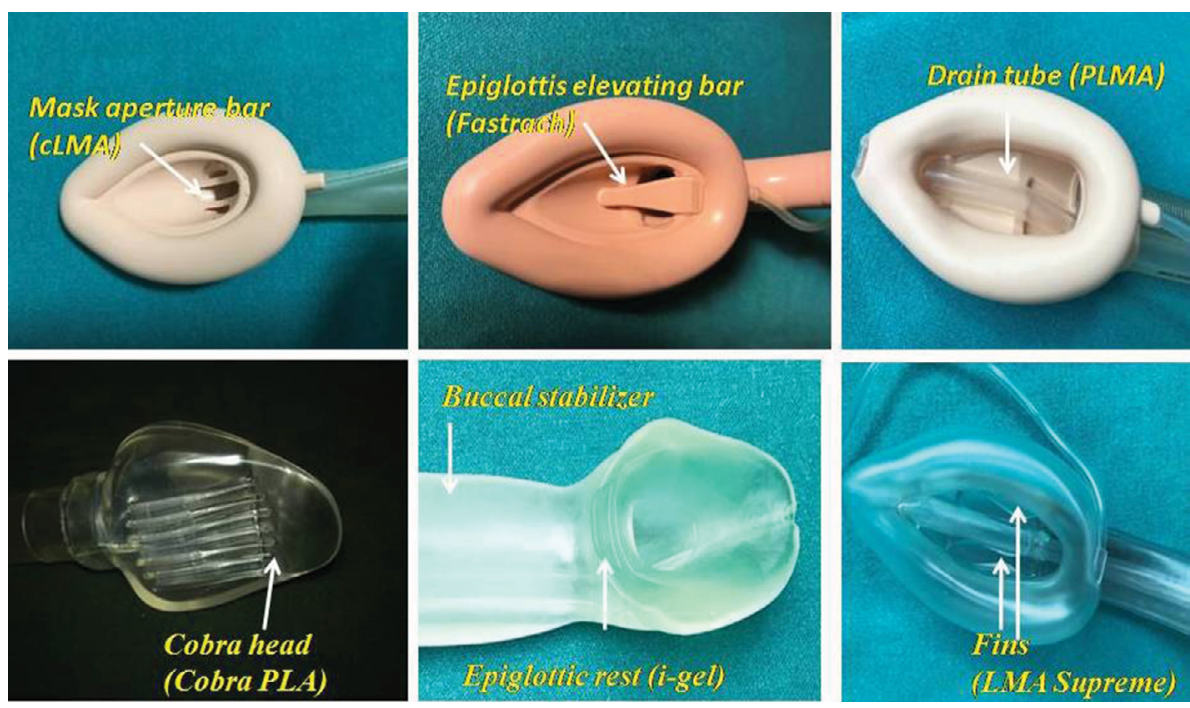

Figure 7 Mask, cuff and bowl of EADs.

Abbreviations: EADs, extraglottic airway devices; cLMA, classic LMA; PLMA, ProSealTM LMA; PLA, Perilaryngeal Airway; LMA, laryngeal mask airway.

modified versions such as epiglottic-elevating bar, Cobra head, epiglottic rest or fins.

Van Zundert et al in a prospective, randomized, crossover comparison of three EADs studied whether EADs with or without MABs result in similar anatomical positions in patients undergoing surgery. The endoscopic evaluation did not demonstrate any difference between the EADs with or without MABs. ${ }^{47}$ The morphometric studies of the adult human epiglottis have reported the width of the epiglottis as $\pm 27 \mathrm{~mm}$ for males and $\pm 21 \mathrm{~mm}$ for females which is in contrast to the width of the aperture of EADs $( \pm 15 \mathrm{~mm})$ and therefore questions the need for the MABs. ${ }^{48}$

The epiglottis-elevating bar is present in the Intubating LMA to lift the epiglottis during intubation. In LMA Supreme, the MABs have been modified into two "fins" to prevent epiglottic downfolding. ${ }^{20}$

The Cobra head of the Cobra PLA, in addition to providing stability, levers the epiglottis away from the airway tube. ${ }^{28}$ In i-gel, an artificial epiglottis and a protective ridge prevent the downfolding or obstruction of the distal opening of the airway (Figure 7). ${ }^{25}$

\section{Airway tube}

The cLMA has a single airway tube with radius of curvature greater than the natural curvature in the mouth as opposed to the LMA Fastrach, LMA Supreme and Ambu Aura LM devices which have anatomical preformed curves. A short wide tube facilitates tracheal intubation and decreases airway resistance, as seen in the Cobra PLA. Preforming the airway tube makes for easy insertion and avoids finger insertion while using the Fastrach or Ambu LMAs. It has been reported that an oval airway cross section of the tube as seen in the LMA Supreme improved stability of the airway, in comparison to PLMA which had a circular cross section. ${ }^{30-32}$

Wire reinforcing of the airway tube makes it nonkinkable and flexible as seen in LMA Flexible and PLMA. This also makes convenient the use of airway tube in nonsupine positions including prone position. The LMA Supreme has two lateral ventilation paths divided by the drain tube (Figure 8).

\section{Drain or gastric tube}

The addition of a second or drain tube, positioned laterally (PLMA, i-gel) or posteriorly (LMA Supreme) to the airway tube, separates the alimentary and respiratory tracts. It allows escape of fluids from the stomach and reduces the risk of gastric insufflation and pulmonary aspiration, helps in optimal placement of the device, determines its correct position and permits monitoring (temperature and cardiac output). Other advantages include opportunity to pass a gastric tube. ${ }^{19}$ The distal drain tubes of LMA Supreme and LMA-Protector have a slant of $10^{\circ}$ thereby allowing the cuff to follow the contours of upper esophageal sphincter which may improve the placement of the device and the hypopharyngeal seal. ${ }^{49}$ However, in the latest modification of LMA Supreme, this slant has been removed. ${ }^{50}$ The Baska mask and LMA-Protector have two drain tubes which emerge proximally as separate ports. ${ }^{51}$

Maximal diameters of orogastric tubes that can be inserted through the gastric channels of the size 3, 4 and 5 of the LMA Supreme are 14, 16 and $16 \mathrm{Fr}$, respectively, compared with 16,16 and $18 \mathrm{Fr}$ for the LMA-Protector and the PLMA. ${ }^{42}$ 

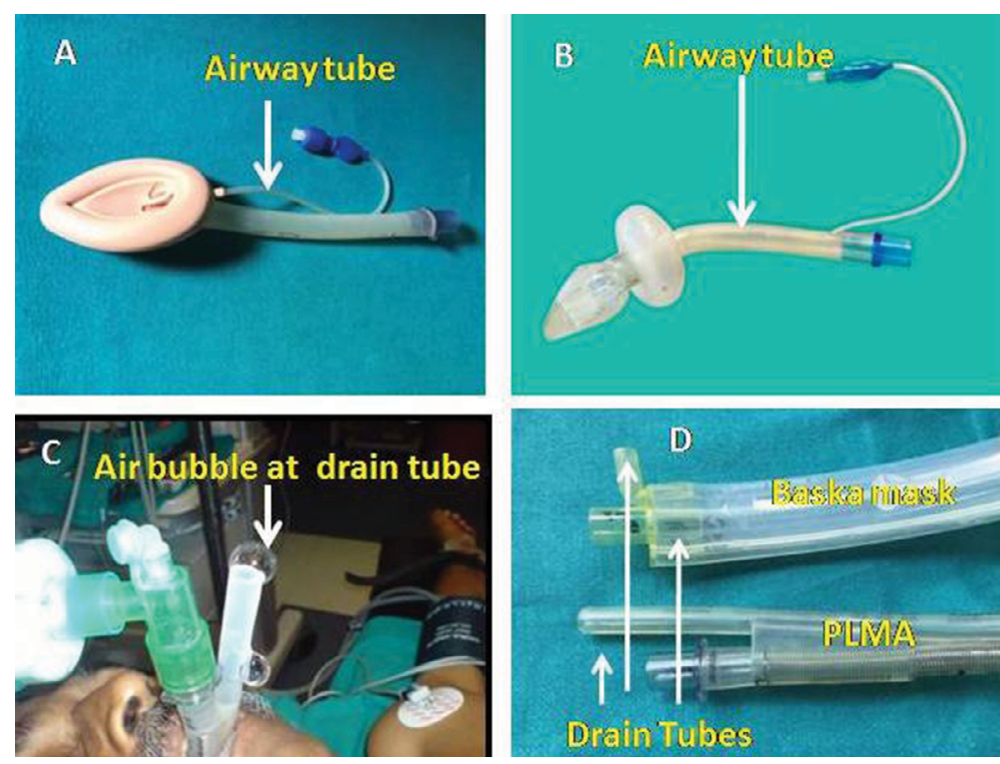

Figure 8 Airway and drain tubes and bite block of EADs: (A) airway tube - cLMA, (B) airway tube - Cobra PLA ${ }^{\mathrm{TM}}$, (C) drain tube - PLMA and (D) drain tube of Baska mask and PLMA.

Abbreviations: EADs, extraglottic airway devices; cLMA, classic laryngeal mask airway; PLA, Perilaryngeal Airway; PLMA, ProSea|TM laryngeal mask airway.

Figure 8 shows the gel displacement test for diagnosing correct placement of PLMA.

\section{Integral bite block/buccal cavity stabilizer}

The length of the integral bite block may vary depending on the size of the device. It helps in preventing the patient biting and obstructing the airway tube, diagnosing device malposition and thus improving patient safety (PLMA, i-gel). ${ }^{20,25}$ The buccal cavity stabilizer in i-gel provides vertical strength to aid insertion. It is wide and concave with a built-in natural curvature and an inherent propensity to adapt its shape to the oropharyngeal curvature of the patient. It eliminates the potential for rotation and also reduces the risk of malposition. ${ }^{25}$

\section{Tab}

The Baska mask tab can improve the insertion success rate by increasing the angulation for easy negotiation of the oropharyngeal curve (Figure 9).

\section{Fixation tab}

It aids in securing the device with adhesive tape and may also help in choosing the proper size of the device (eg, LMAProtector and LMA Supreme). The tab should sit between 0.5 and $2.0 \mathrm{~cm}$ from the upper lip; otherwise, a different size should be chosen (Figure 9). ${ }^{42}$

\section{Tracheal conduit/integrated fiber optics}

The Fastrach was primarily designed for tracheal intubation through the mask. It is not easy to perform endotracheal
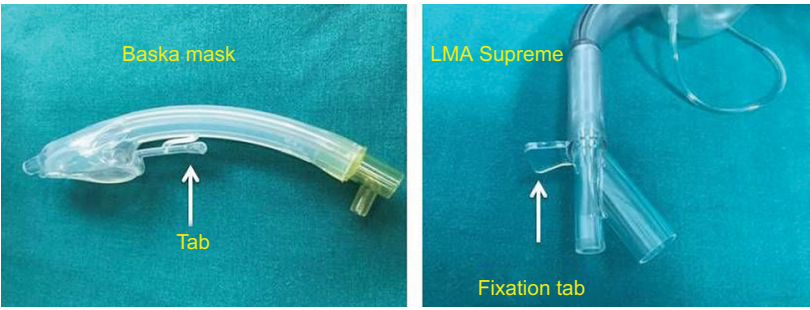

Figure $9 \mathrm{Tab}$ (Baska) and fixation tab (LMA Supreme $\left.{ }^{\mathrm{TM}}\right)$.

Abbreviation: LMA, laryngeal mask airway.

intubation through PLMA and LMA Supreme as they have narrow airway tubes in comparison to Ambu airway mask, i-gel, Baska mask and LMA-Protector. Therefore, they need extra adjuncts, such as a bronchoscopic/Aintree Intubation Catheter-guided technique, to place an adequate size tube through them. ${ }^{52}$ The airway lumen of the LMA-Protector (maximal internal diameter $13 \mathrm{~mm}$ ) is wide enough to pass an adequately sized adult tracheal tube directly, without the use of an intermediate exchange catheter (ie, a maximal size tracheal tube of $6.5,7.5$ and $7.5 \mathrm{~mm}$ for the device sizes 3,4 and 5 respectively). As such, use of the LMA-Protector as a conduit for fiber optic-assisted rescue intubation should be easier to accomplish than using an LMA Supreme or PLMA. However, these hypotheses require investigation as no clinical evidence is available.

The LMA CTrach and the Totaltrack VLM allow simultaneous ventilation and intubation with continuous visualization of the laryngeal structures and the dynamics of tracheal intubations due to integrated fibreoptics. ${ }^{18,32}$ The Totaltrack VLM has a dedicated gastric aspiration tube and laryngeal tube for aspiration of internal mask secretions (Figure 10). 

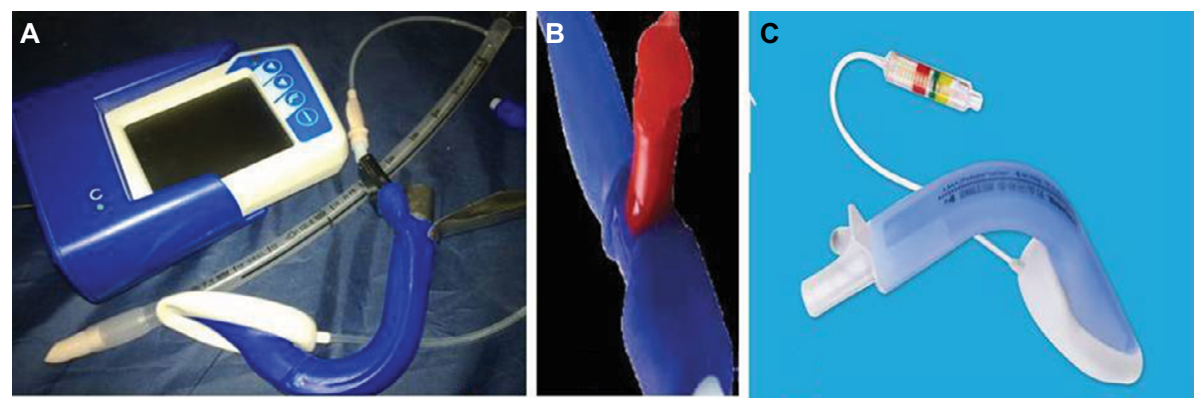

Figure 10 (A) LMA CTrach. (B) Red Plug of PLMA. (C) Baska with Integrated Cuff Pilot ${ }^{\mathrm{TM}}$.

Abbreviations: LMA, laryngeal mask airway; PLMA, ProSeal ${ }^{T M}$ LMA.

\section{Red Plug/Integrated Cuff Pilot ${ }^{\mathrm{TM}}$}

Red Plug or the manual vent is a modification of the PLMA and is incorporated into the pilot balloon. It should be kept open during autoclaving to prevent damage such as herniation of the cuff from resultant built-up of undue pressures due to residual fluid or air. ${ }^{53}$ Integrated Cuff Pilot has an integrated cuff pressure indicator for single-use airway management devices (LMA-Protector) that allows continuous cuff pressure monitoring and is another improvement of the pilot balloon (Figure 10). ${ }^{42}$

\section{Construction material issues}

Several materials have been tried for the construction of the different components of the EADs varying from latex and silicone to polyvinylchloride (PVC). Vulcanized rubber is natural rubber with additives such as sulfur and other curatives. Vulcanization makes rubber much stronger and more flexible and increases resistance to heat and other environmental conditions. Vulcanized rubber cuffs obtained from the Goldman nasal mask were used for the first prototypes of LMA in $1981 .{ }^{14}$ Later on, they were replaced by materials such as latex and medical-grade silicone.

Latex is a mixture of organic compounds produced by some plants in special cells called caticifers. There is a high incidence of allergy reported with the use of latex-based devices: $1-2 \%$ in normal population and rising up to $10 \%$ among the health care professionals. ${ }^{54}$ Medical-grade silicone is a near-ideal construction material with an indefinite shelf life.$^{53}$ Silicone rubber is an elastomer (rubber-like material) composed of silicone, a polymer containing silicon along with carbon, hydrogen and oxygen. Silicone rubber offers good resistance to extreme temperatures, being able to operate normally from -100 to $300^{\circ} \mathrm{C}\left(-148\right.$ to $\left.572{ }^{\circ} \mathrm{F}\right) .{ }^{55}$ Silicone offers the advantages of making the device reusable as it allows mechanical cleaning and sterilization. The cuffs of the reusable LMAs and the Baska mask are manufactured from a silicone. The distal tip of the laryngeal blade of the
Totaltrack VLM is protected by a patented silicone sleeve, decreasing the possibility of tip breakage and tissue injury. ${ }^{32}$

Medical-grade PVC was used to construct disposable devices to accommodate concerns about disease transmission and the costs of cleaning and sterilization of reusable EADs. The first disposable EAD was the LMA Unique, made of PVC. ${ }^{56}$ Most available disposable LMs on the market, such as the LMA Supreme, AuraOnce or Solus LM, are made of PVC. The Cobra PLA and Cobra PLUS contain PVC with different softness. The head of the Cobra PLUS device is rigid, while the pharyngeal cuff is soft. ${ }^{27}$

Phthalate-free PVC has been employed for manufacturing Ambu AuraGain and the recently introduced LMA-Protector. ${ }^{42,57} \mathrm{Phthalates}$ are used primarily as plasticizers in flexible PVC products to impart flexibility to plastics. Their use is approved in several medical devices. ${ }^{58,59}$ Components used in plastics, such as bisphenol A, polybrominated diphenyl ethers, tetrabromobisphenol A and phthalates, are released from plastic products and are also known as endocrinedisrupting compounds owing to their ability to modulate the endocrine system. ${ }^{60}$

The immature male reproductive tract is the most sensitive to phthalates, with exposure resulting in increased incidence of undescended testes, decreased testicular weight, decreased anogenital distance and other effects. ${ }^{61}$ Human studies increasingly report associations of phthalates with various adverse reproductive effects on steroid genesis and luteal function. ${ }^{62}$ Ethylene-vinyl acetate copolymer, a plastic material with limited flexibility, has been used for manufacturing the SLIPA. This material is hard, and there were reports of more frequent traces of blood on the device. ${ }^{63}$

A very soft gel-like transparent thermoplastic elastomer called styrene ethylene butadiene styrene (SEBS) has been used to construct the bowl of the i-gel airway which is a cuffless device. ${ }^{64}$ Initially, it was expected that this material may warm up to body temperature and change its properties with subsequent improvement in perilaryngeal seal. This specula- 
tion has not been confirmed in clinical practice. ${ }^{65}$ SEBS is also very stable in high altitude and hyperbaric conditions which might create potential for its use during helicopter transfers and in diving medicine. ${ }^{26}$

The inflation valve of the PLMA is similar to that of the cLMA and Intubating LMA. It has a white polypropylene core and a stainless steel spring. ${ }^{53}$ The MR-compatible EADs such as MR-safe LMA, Solus LMA and Ambu disposable LM have nonferromagnetic material in the valve assembly. i-gel and Ambu AuraGain are also MR compatible. The PLMA contains metal wires which makes it MR incompatible.

\section{Available sizes}

Earlier, only the adult sizes of EADs were available. Presently, both adult and pediatric sizes are available for most of the devices. However, pediatric sizes are not available for Intubating LMA. All sizes are available for Cobra PLA including a pediatric 0.5 size. There is no standardization of the sizes. Manufacturers have their own sizes of the devices. The appropriate size for any patient is device specific mostly on weight basis; however, it may also be based on gender.

\section{Functional evolution}

The LMA fills the gap between a face mask and a tracheal tube. The entry of the LMA in the anesthesiologists airway armamentarium changed the way anesthesiologists approached the management of the airway inexorably changing daily practice and algorithms. The LMA allowed the anesthesiologists to be hands free and also broadened the scope of EADs. This popularity stems directly from their ease of use, simplicity of training, predictability and speed of insertion. These devices have several advantages over the endotracheal tube like increased speed and ease of placement, improved hemodynamic stability at induction and during emergence of anesthesia, reduced anesthetic requirements, lower frequency of coughing during emergence and lower incidence of sore throat. ${ }^{21}$

The last 30 years of clinical anesthesia practice have witnessed several modifications with increasing use of these devices and a widening scope of the EADs right from conduits for tracheal intubation in difficult airway scenarios or as airway adjuncts in resuscitation, cardiac arrest or in prehospital medicine in pediatric and adult population leading to several important improvements in the design and functional evolution of the device. ${ }^{66,67}$ LMA has been used for delivery of surfactant in preterm babies. ${ }^{68}$

EADs are not suitable alternatives for prolonged ventilation in the ICU, and intensivists without anesthesia background are not familiar with these devices. However, the devices have been used in ICU setting for failed and difficult intubation, postoperative ventilation and for their role in percutaneous dilatational tracheostomy and postoperative care. ${ }^{69,70}$

This enthusiastic acceptance has triggered the search for new designs and use in previously contraindicated locations, patients and surgery, thus spreading the reach of the airway safety net the EADs impart. Since these new devices provide alternate ways to secure the airway, they can help avert the disastrous consequences of failed face mask ventilation or intubation and as such have now been accepted by the anesthesia community.

This functional evolution would of course have been impossible without appropriate patient selection, device size, knowledge and experience of optimum and atraumatic device placement and maintenance of adequate OSP.

The Vortex approach is a new thought process based on the principle that there are three "nonsurgical" techniques to establish a patent airway: use of a face mask, a supraglottic airway or an endotracheal tube. ${ }^{71}$

\section{Complications and safety issues}

The correct use of EADs is seldom associated with serious complications as the majority of them are minor in nature and are often associated with a divergence from the manufacturers' advice on usage of these devices. Postoperative sore throat, dysphagia, pain on swallowing or hoarseness and nerve injuries may result from excessive unmonitored cuff volume and pressure of the devices on cervical vasculature and microcirculation of the pharyngeal mucosa. Paying attention to the recommended cuff pressures may decrease the incidence of these complications. ${ }^{72}$

Tracheal intubation is accompanied by increased airway resistance resulting from turbulent flow due to a tube within a tube (tracheal tube within the trachea), and this fact inspired Brain to invent the LMA. There is recorded actual and potential damage associated with the use of tracheal tube during routine anesthesia, and this remains a driving force for the development of future EADs. A meta-analysis involving 29 randomized prospective controlled trials in adults compared LMAs versus tracheal tube for airway maintenance in patients under general anesthesia and found that LMAs have a lower incidence of postoperative sore throat, hoarseness, coughing and laryngospasm during recovery from anesthesia. ${ }^{73}$ Similar results along with decreased incidence of vomiting were confirmed in pediatric population by another RCT. ${ }^{74}$ 
A disadvantage of the LMAs was the increased probability of failure to insert the device on the first attempt. There is a 5-10\% failure rate of insertion of these devices on the first attempt due to anatomical differences in the perilaryngeal area, and it may be advisable that the operator should keep the sealing sites of these devices in mind. If insertion fails with one device, then the alternate chosen EAD should have a different sealing site to ensure successful placement (failure rate less than $1 \%) .{ }^{11}$

There has been the fear of aspiration associated with EAD use, though the clinical evidence of pulmonary aspiration using the LMA was comparable to anesthesia administered with an endotracheal tube. Evidence-based RCTs are not easy to get since the overall incidence of pulmonary aspiration associated with the use of EADs is low and RCTs would require about a million patients if a significant conclusion ( $50 \%$ decrease in aspiration and a power of $80 \%$ ) is to be reached. ${ }^{75,76}$ There has, however, been a large prospective study of 65,712 patients comparing aspiration associated with tracheal intubation versus LMAs. There were seven cases of aspiration with the tracheal tube against three cases where the LMA had been used (cLMA and LMA Unique). ${ }^{77}$ Sharma et al tested the efficacy and safety of the PLMA as a ventilatory device for a variety of commonly performed elective laparoscopic surgeries in 1,000 patients and concluded that in experienced hands and following a strict protocol of insertion, the PLMA is an efficient and safe tool for airway management. Twenty-five $(2.5 \%)$ patients showed gastric regurgitation, suctioned through the esophageal channel of the PLMA, but no case of pulmonary aspiration was detected. $^{78}$

A Cochrane database comparing EADs versus tracheal intubation for airway management during general anesthesia in obese patients $\left(\mathrm{BMI}<35 \mathrm{~kg} / \mathrm{m}^{2}\right)$ concluded that there is inadequate information to draw conclusion about safety of these devices and commented only on one design of EAD (PLMA) in these patients. During routine and laparoscopic surgery, PLMAs may take a few seconds longer to insert: a failure rate of $3-5 \%$ and higher leak fraction. PLMAs provide significant improvement in oxygenation during and after surgery, and reduced postoperative coughing, suggesting better recovery of patients. ${ }^{79}$

The 4th National Audit Project of the Royal College of Anesthetists and the Difficult Airway Society (NAP4) examined issues related to the EADs and found that the commonest complication associated with anesthesia was airway complication and EADs use-related aspiration was a contributor to this. NPA4 also revealed that $80 \%$ of EADs used for airway management in Britain were first-generation devices (eg, cLMA and LMs). The complications were more in the obese population where a first-generation device had been employed. The report recommended use of the secondgeneration devices to improve the outcome, since these devices have been shown to be safer than the first-generation devices. ${ }^{80}$ This safety rests on the understanding by the concerned anesthesiologists of the device design, patient factors as well as the surgical scenario.

Cook and Kelly have devised a safety scoring system to help decide the choice of EAD which suits the needs of a particular patient. ${ }^{76}$ Greenland and Irwin have elaborated on seven axioms for selecting difficult airway devices. ${ }^{81}$

Pharyngeal rupture, pneumomediastinum, mediastinitis or arytenoid dislocation and nerve injuries are other very rare but serious complications of EADs. ${ }^{82-84}$

EADs play a major role in difficult airway scenario and have a place in the latest American Society of Anesthesiologists and Obstetric Anesthetists' Association and DAS guidelines for difficult airway management. ${ }^{85,86}$ Knowing the physical characteristics of the airway device helps in generating hypotheses and better understanding of the working of an equipment before using it in clinical practice. ${ }^{51}$

\section{Limitations of the study}

We were unable to get all the relevant data. The maximum number of studies is available for cLMA which is not much in use, and it is recommended that it should be withdrawn as it has served its purpose. The EADs are continuously evolving, and since new devices are introduced each year (about two new EADs every year), there is insufficient literature available for every device, so evidence-based conclusion cannot be drawn from the studies. It is also becoming increasingly difficult to conduct research because of safety concerns. Reporting bias cannot also be ruled out.

\section{Conclusion}

The last three decades have witnessed several new airway devices and techniques with radical changes in airway practice and management. The introduction of EADs has resulted in a paradigm shift in airway management from a face mask versus tracheal tube to face mask versus EAD versus tracheal tube model. New EADs such as LMA-Protector, Baska mask and miscellaneous multipurpose device (eg, Totaltrack VLM) have been new additions to the EADs family, but their impact on patient safety and outcome still awaits scientific evaluation. Aspiration remains the single most-dreaded complication of these devices. Pharyngolaryngeal morbidity 
and nerve injuries may be avoided to a large extent by paying careful attention to insertion and careful monitoring of the cuff pressure of the EADs. Providing adequate oxygenation and ventilation remains the gold standard of any patient safety goal and airway management technique. The anesthesia community is still waiting for the ideal EAD: simple design, excellent seal, high success rate of insertion on the first attempt even in the hands of novices, reliable drainage mechanism, zero aspiration, use in a full-stomach patient with a difficult airway in the emergent situation, low incidence of postoperative discomfort, affordable, with a low risk-benefit ratio, and in a nutshell with all the desirable features of an endotracheal tube and none of its drawbacks.

\section{Disclosure}

The authors report no conflicts of interest in this work.

\section{References}

1. ASTM International. ASTM standards for healthcare services, products and technology. Available from: https://www.astm.org/ABOUT/images/ Medical_sector.pdf. Accessed November 21, 2016.

2. Sinha PK, Misra S. Supraglottic airway devices other than laryngeal mask airway and its prototypes. Indian J Anaesth. 2005;49(4): 281-292.

3. Pandit JJ, Popat MT, Cook TM, et al. The Difficult Airway Society 'ADEPT' guidance on selecting airway devices: the basis of a strategy for equipment evaluation. Anaesthesia. 2011;66(8):726-737.

4. Brimacombe J. A proposed classification system for extraglottic airway devices. Anesthesiology. 2004;101(2):559.

5. Miller DM. A proposed classification and scoring system for supraglottic sealing airways: a brief review. Anesth Analg. 2004;99(5):1553-1559; table of contents.

6. Miller DM. Re-classification of extraglottic/supralaryngeal airway devices. In: Michalek P, Donaldson W, editors. The i-Gel Supraglottic Airway. New York: Nova Biomedical; 2013:15-28.

7. Hernandez MR, Klock PA Jr, Ovassapian A. Evolution of the extraglottic airway: a review of its history, applications, and practical tips for success. Anesth Analg. 2012;114(2):349-368.

8. Ramachandran SK, Kumar AM. Supraglottic airway devices. Respir Care. 2014;59(6):920-932.

9. Miller DM, Light D. Laboratory and clinical comparisons of the Streamlined Liner of the Pharynx Airway (SLIPA) with the laryngeal mask airway. Anaesthesia. 2003;58(2):136-142.

10. Cook T, Howes B. Supraglottic airway devices: recent advances. Contin Educ Anaesth Crit Care Pain. 2011;11(2):56-61.

11. Michálek P, Miller DM. Airway management evolution - in a search for an ideal extraglottic airway device. Prague Med Rep. 2014;115(3-4): 87-103.

12. Shipway F. Airway for intranasal operations. Br Med J. 1935;1:767.

13. Leech BC. The pharyngeal bulb gasway: a new aid in cyclopropane anesthesia. Anesth Analg. 1937;16(1):22-25.

14. Brain AI. The laryngeal mask - a new concept in airway management. Br J Anaesth. 1983;55(8):801-805.

15. HowEquipmentWorks.com. Available from: https://www.howequipmentworks.com. Accessed October 12, 2016.

16. Brimacombe J, Keller C. A comparison of the flexible and standard laryngeal mask airways. Can J Anaesth. 1999;46(6):558-563.

17. Baskett PJ, Parr MJ, Nolan JP. The intubating laryngeal mask. Results of a multicentre trial with experience of 500 cases. Anaesthesia. 1998;53(12):1174-1179.
18. Liu EH, Goy RW, Chen FG. The LMA CTrach a new laryngeal mask airway for endotracheal intubation under vision: evaluation in 100 patients. Br J Anaesth. 2006;96(3):396-400.

19. Brain AI, Verghese C, Strube PJ. The LMA 'ProSeal'-a laryngeal mask with an oesophageal vent. Br J Anaesth. 2000;84(5):650-654.

20. Verghese C, Ramaswamy B. LMA Supreme - a new single-use LMA with gastric access: a report on its clinical efficacy. $\mathrm{Br} J$ Anaesth. 2008;101(3):405-410.

21. Brimacombe J. The advantages of the LMA over the tracheal tube or facemask: a meta-analysis. Can J Anaesth. 1995;42(11):1017-1023.

22. Donaldson W, Abraham A, Deighan M, Michalek P. I-gel ${ }^{\mathrm{TM}}$ vs. AuraOnce $^{\mathrm{TM}}$ laryngeal mask for general anaesthesia with controlled ventilation in paralyzed patients. Biomed Pap Med Fac Univ Palacky Olomouc Czech Repub. 2011;155(2):155-164.

23. Miller DM, Lavelle M. A streamlined pharynx airway liner: a pilot study in 22 patients in controlled and spontaneous ventilation. Anesth Analg. 2002;94(3):759-761; table of contents.

24. Vaida SJ, Gaitini D, Ben-David B, Somri M, Hagberg CA, Gaitini LA. A new supraglottic airway, the Elisha Airway Device: a preliminary study. Anesth Analg. 2004;99(1):124-127.

25. Levitan RM, Kinkle WC. Initial anatomic investigations of the I-gel airway: a novel supraglottic airway without inflatable cuff. Anaesthesia. 2005;60(10):1022-1026.

26. Michalek P, Donaldson W, Theiler L. The use of the i-gel in anaesthesia - facts and fiction in 2013. Trends Anaesth Crit Care. 2013;3(5): 246-251.

27. Hooshangi H, Wong DT. Brief review: the Cobra Perilaryngeal Airway (CobraPLA) and the Streamlined Liner of the Pharyngeal Airway (SLIPA) supraglottic airways. Can J Anaesth. 2008;55(3):177-185.

28. Asai T, Shingu T. The laryngeal tube. Br J Anaesth. 2005;95(6): 729-736.

29. Asai T, Goy RW, Liu EH. Cricoid pressure prevents placement of the laryngeal tube and laryngeal tube-suction II. Br J Anaesth. 2007;99(2):282-285.

30. Bergold MN, Kahle S, Schultzik T, Bücheler M, Byhahn C. [Intubating laryngeal tube suction disposable: initial clinical experiences with a novel device for endotracheal intubation]. Anaesthesist. 2016;65(1): 30-35. German [with English abstract].

31. Alexiev V, Salim A, Kevin LG, Laffey JG. An observational study of the Baska ${ }^{\circledR}$ mask: a novel supraglottic airway. Anaesthesia. 2012; 67(6):640-645.

32. The 1 st device that allows simultaneous ventilation \& intubation with continuous visualization. Totaltrack VLM. Available from: http://www. medcomtechgroup.com/media/files/Medcomflow/producto/Catalogue TotalTrack_VLM_-_English_(LR).pdf. Accessed November 29, 2016.

33. Neumar RW, Shuster M, Callaway CW, et al. Part 1: executive summary: 2015 American Heart Association guidelines update for cardiopulmonary resuscitation and emergency cardiovascular care. Circulation. 2015;132(18 Suppl 2):S315-S367.

34. Kikuchi T, Kamiya Y, Ohtsuka T, Miki T, Goto T. Randomized prospective study comparing the laryngeal tube suction II with the ProSeal laryngeal mask airway in anesthetized and paralyzed patients. Anesthesiology. 2008;109(1):54-60.

35. Akça $\mathrm{O}$, Wadhwa A, Sengupta $\mathrm{P}$, et al. The new perilaryngeal airway (CobraPLA) is as efficient as the laryngeal mask airway (LMA) but provides better airway sealing pressures. Anesth Analg. 2004;99(1): 272-278.

36. Zhu W, Wei X. A randomized comparison of pediatric-sized Streamlined Liner of Pharyngeal Airway and Laryngeal Mask Airway-Unique in paralyzed children. Paediatr Anaesth. 2016;26(5):557-563.

37. Woo YC, Cha SM, Kang H, et al. Less perilaryngeal gas leakage with SLIPA $^{\mathrm{TM}}$ than with LMA-ProSeal ${ }^{\mathrm{TM}}$ in paralyzed patients. Can $J$ Anaesth. 2011;58(1):48-54.

38. Abdellatif AA, Ali MA. Comparison of streamlined liner of the pharynx airway $\left(\right.$ SLIPA $^{\mathrm{TM}}$ ) with the laryngeal mask airway Proseal ${ }^{\mathrm{TM}}$ for lower abdominal laparoscopic surgeries in paralyzed, anesthetized patients. Saudi J Anaesth. 2011;5(3):270-276. 
39. Park SK, Choi GJ, Choi YS, Ahn EJ, Kang H. Comparison of the i-gel and the laryngeal mask airway proseal during general anesthesia: a systematic review and meta-analysis. PLoS One. 2015;10(3): e0119469.

40. Shariffuddin II, Teoh WH, Tang E, Hashim N, Loh PS. Ambu ${ }^{\circledR}$ AuraGain $^{\mathrm{TM}}$ versus LMA Supreme ${ }^{\mathrm{TM}}$ Second Seal ${ }^{\mathrm{TM}}$ : a randomised controlled trial comparing oropharyngeal leak pressures and gastric drain functionality in spontaneously breathing patients. Anaesth Intensive Care. 2017;45(2):244-250.

41. Keller C, Brimacombe J. Mucosal pressure and oropharyngeal leak pressure with the ProSeal versus laryngeal mask airway in anaesthetized paralysed patients. Br J Anaesth. 2000;85(2):262-266.

42. LMA Protector. Available from: http://www.teleflex.com. Accessed November 30, 2016.

43. Brain AI. The development of the Laryngeal Mask - a brief history of the invention, early clinical studies and experimental work from which the Laryngeal Mask evolved. Eur J Anaesthesiol Suppl. 1991;4:5-17.

44. Al-Shaikh B, Pilcher D. Is there a need for the epiglottic bars in the laryngeal mask airway? Can J Anaesth. 2003;50(2):203-204.

45. Van Zundert AA, Fonck K, Al-Shaikh B, Mortier E. A comparison of the LMA-Classic with the new disposable Soft Seal laryngeal mask in spontaneously breathing adult patients. Anesthesiology. 2003;99(5):1066-1071.

46. Van Zundert A, Brimacombe J, Kamphuis R, Haanschoten M. The anatomical position of three extraglottic airway devices in patients with clear airways. Anaesthesia. 2006;61(9):891-895.

47. Van Zundert TC, Hendrickx JF, De Witte JL, Wong DT, Cattano D, Brimacombe JR. Do mask aperture bars of extraglottic airway devices prevent prolapse of epiglottis causing airway obstruction? A randomized crossover trial in anesthetized adult patients. J Clin Anesth. 2016;31:231-237

48. Kano M, Shimizu Y, Okayama K, Igari T, Kikuchi M. A morphometric study of age-related changes in adult human epiglottis using quantitative digital analysis of cartilage calcification. Cells Tissues Organs. 2005;180(2):126-137.

49. Gaitini L, Vaida $\mathrm{S}$. Is the newly designed distal tip of the LMA supreme an advantage or a disadvantage? J Clin Anesth. 2015;27(2): 181-182.

50. New LMA Supreme ${ }^{\mathrm{TM}}$ Design Enhancements. Available from: http:// www.teleflex.com/emea/documentLibrary/documents/940773-000001_ LMA_Supreme-cuff-comparison-Poster_1408_PDF-only.pdf. Accessed April 17, 2017.

51. Van Zundert AA, Skinner MW, Van Zundert TC, Luney SR, Pandit JJ. Value of knowing physical characteristics of the airway device before using it. Br J Anaesth. 2016;117(1):12-16.

52. van Zundert TC, Wong DT, van Zundert AA. The LMA-Supreme ${ }^{\mathrm{TM}}$ as an intubation conduit in patients with known difficult airways: prospective evaluation study. Acta Anaesthesiol Scand. 2013;57(1):77-81.

53. Brimacombe JR. Laryngeal MaskAnesthesia: Principles and Practice. 2nd ed. London: WB Saunders; 2005.

54. Pollart SM, Warniment C, Mori T. Latex allergy. Am Fam Physician. 2009;80(12):1413-1418.

55. RTV silicone rubber. Available from: http://www.shinetsusiliconeglobal.com/catalog/pdf/rubber_e.pdf. Accessed October 10, 2016.

56. Verghese C, Berlet J, Kapila A, Pollard R. Clinical assessment of the single use laryngeal mask airway-the LMA-unique. Br J Anaesth. 1998;80(5):677-679.

57. AmbuAuraGain. Available from: http://www.ambu.com/corp/products/ anaesthesia/product/auragain \%E2\%84\%A2_disposable_laryngeal_ mask-prod18315.aspx. Accessed April 10, 2017.

58. Lovekamp-Swan T, Davis BJ. Mechanisms of phthalate ester toxicity in the female reproductive system. Environ Health Perspect. 2003;111(2):139-145.

59. Blount BC, Milgram KE, Silva MJ, et al. Quantitative detection of eight phthalate metabolites in human urine using HPLC-APCI-MS/MS. Anal Chem. 2000;72(17):4127-4134
60. Talsness CE, Andrade AJ, Kuriyama SN, Taylor JA, vom Saal FS. Components of plastic: experimental studies in animals and relevance for human health. Philos Trans $R$ Soc Lond B Biol Sci. 2009;364(1526):2079-2096.

61. Swan SH, Main KM, Liu F, et al; Study for Future Families Research Team. Decrease in anogenital distance among male infants with prenatal phthalate exposure. Environ Health Perspect. 2005;113(8): 1056-1061.

62. Romani F, Tropea A, Scarinci E, et al. Endocrine disruptors and human reproductive failure: the in vitro effect of phthalates on human luteal cells. Fertil Steril. 2014;102(3):831-837.

63. Lange M, Smul T, Zimmermann P, Kohlenberger R, Roewer N, Kehl F. The effectiveness and patient comfort of the novel streamlined pharynx airway liner (SLIPA) compared with the conventional laryngeal mask airway in ophthalmic surgery. Anesth Analg. 2007;104(2): 431-434.

64. Richez B, Saltel L, Banchereau F, Torrielli R, Cros AM. A new single use supraglottic airway device with a noninflatable cuff and an esophageal vent: an observational study of the i-gel. Anesth Analg. 2008; 106(4):1137-1139.

65. Nishiyama T, Kohno Y, Kim HJ, Shin WJ, Yang HS. The effects of prewarming the I-gel on fitting to laryngeal structure. Am J Emerg Med. 2012;30(9):1756-1759.

66. Wong DT, Yang JJ, Mak HY, Jagannathan N. Use of intubation introducers through a supraglottic airway to facilitate tracheal intubation: a brief review. Can J Anaesth. 2012;59(7):704-715.

67. Henlin T, Michalek P, Tyll T, Hinds JD, Dobias M. Oxygenation, ventilation, and airway management in out-of-hospital cardiac arrest: a review. Biomed Res Int. 2014;2014:376871.

68. Parmigiani S. Non-invasive surfactant administration in newborn babies. Infant. 2011;7(4):112-115

69. Russo SG, Moerer O, Nickel EA, Goetze B, Timmermann A, Quintel M. [Extraglottic airway devices in the intensive care unit]. Anaesthesist. 2010;59(6):555-563. German [with English abstract].

70. Russo SG, Goetze B, Troche S, Barwing J, Quintel M, Timmermann A. LMA-ProSeal for elective postoperative care on the intensive care unit: a prospective, randomized trial. Anesthesiology. 2009;111(1): 116-121.

71. Chrimes N. The Vortex: a universal 'high-acuity implementation tool' for emergency airway management. Br J Anaesth. 2016;117(Suppl 1): i20-i27.

72. Michalek P, Donaldson W, Vobrubova E, Hakl M. Complications associated with the use of supraglottic airway devices in perioperative medicine. Biomed Res Int. 2015;2015:746560.

73. Yu SH, Beirne OR. Laryngeal mask airways have a lower risk of airway complications compared with endotracheal intubation: a systematic review. J Oral Maxillofac Surg. 2010;68(10):2359-2376.

74. Patki A. Laryngeal mask airway vs. the endotracheal tube in paediatric airway management: a meta-analysis of prospective randomised controlled trials. Indian J Anaesth. 2011;55(5):537-541.

75. Sidaras G, Hunter JM. Is it safe to artificially ventilate a paralysed patient through the laryngeal mask? The jury is still out. Br J Anaesth. 2001;86(6):749-753.

76. Cook TM, Kelly FE. Time to abandon the 'vintage' laryngeal mask airway and adopt second-generation supraglottic airway devices as first choice. Br J Anaesth. 2015;115(4):497-499.

77. Bernardini A, Natalini G. Risk of pulmonary aspiration with laryngeal mask airway and tracheal tube: analysis on 65712 procedures with positive pressure ventilation. Anaesthesia. 2009;64(12):1289-1294.

78. Sharma B, Sood J, Sahai C, Kumra VP. Efficacy and safety performance of ProSeal ${ }^{\mathrm{TM}}$ laryngeal mask airway in laparoscopic surgery: experience of 1000 cases. Indian J Anaesth. 2008;52(3):288-296.

79. Nicholson A, Cook TM, Smith AF, Lewis SR, Reed SS. Supraglottic airway devices versus tracheal intubation for airway management during general anaesthesia in obese patients. Cochrane Database Syst Rev. 2013;(9):CD010105. 
80. Cook TM, Woodall N, Harper J, Benger J; Fourth National Audit Project. Major complications of airway management in the UK: results of the Fourth National Audit Project of the Royal College of Anaesthetists and the Difficult Airway Society. Part 2: intensive care and emergency departments. Br J Anaesth. 2011;106(5):632-642.

81. Greenland KB, Irwin MG. Airway management--'spinning silk from cocoons’ ( - Chinese idiom). Anaesthesia. 2014;69(4):296-300.

82. Paciuc M. Deep neck abscess and mediastinitis after laryngeal mask anesthesia. Anesth Analg. 2009;108(4):1356-1357.

83. Yegappan C, Redmond E, LeDez K. Anterior mediastinitis following traumatic laryngeal mask placement. Can J Anaesth. 2007;54(Suppl 1): 44568.

84. Atalay YO, Kaya C, Aktas S, Toker K. A complication of the laryngeal mask airway: pharyngolaryngeal rupture and pneumomediastinum. Eur J Anaesthesiol. 2015;32(6):439-440.
85. Apfelbaum JL, Hagberg CA, Caplan RA, et al; American Society of Anesthesiologists Task Force on Management of the Difficult Airway. Practice guidelines for management of the difficult airway: an updated report by the American Society of Anesthesiologists Task Force on Management of the Difficult Airway. Anesthesiology. 2013;118(2): 251-270.

86. Mushambi MC, Kinsella SM, Popat M, et al; Obstetric Anaesthetists' Association; Difficult Airway Society. Obstetric Anaesthetists' Association and Difficult Airway Society guidelines for the management of difficult and failed tracheal intubation in obstetrics. Anaesthesia. 2015;70(11):1286-1306.
Medical Devices: Evidence and Research

\section{Publish your work in this journal}

Medical Devices: Evidence and Research is an international, peerreviewed, open access journal that focuses on the evidence, technology, research, and expert opinion supporting the use and application of medical devices in the diagnosis, monitoring, treatment and management of clinical conditions and physiological processes. The identification of novel

\section{Dovepress}

devices and optimal use of existing devices which will lead to improved clinical outcomes and more effective patient management and safety is a key feature. The manuscript management system is completely online and includes a quick and fair peer-review system. Visit http://www. dovepress.com/testimonials.php to read real quotes from authors.

Submit your manuscript here: https://www.dovepress.com/medical-devices-evidence-and-research-journal 